Article

\title{
Versatile bifunctional nitrogen-doped porous carbon derived from biomass in catalytic reduction of 4-nitrophenol and oxidation of styrene
}

\author{
Jiangyong Liu a,*, Jinxing Li a, Rongfei Ye a, Xiaodong Yan ${ }^{\text {b }}$, Lixia Wang a, Panming Jian ${ }^{\text {a }}$ \\ a School of Chemistry and Chemical Engineering, Yangzhou University, Yangzhou 225002, Jiangsu, China \\ ${ }^{\mathrm{b} S}$ School of Chemical and Material Engineering, Jiangnan University, Wuxi 214122, Jiangsu, China
}

\section{A R T I C L E I N F O}

\section{Article history:}

Received 20 November 2019

Accepted 28 December 2019

Published 5 August 2020

\section{Keywords:}

Nitrogen-doping

Carbon

Biomass

4-Nitrophenol

Styrene

\begin{abstract}
A B S T R A C T
The scarcity and weak durability of metal, especially precious metal catalysts are big obstacles for their large-scale application in many reactions. The state-of-the-art of the catalytic science prefers such type of catalysts, which can replace metal-based catalysts to alleviate energy and environmental crises and exhibit catalytic performance comparable to or even exceeding these metal catalysts. Herein, we report that $\mathrm{N}$-doped porous carbon (NKC) derived from cheap and abundant radish can be employed as versatile and efficient bifunctional catalysts in both the catalytic reduction of 4-nitrophenol (NRR) and oxidation of styrene (SOR). The series of NKC catalysts were prepared with a simple and facile one-pot strategy by coupling the N-doping, carbonization and $\mathrm{KOH}$ activation processes. These catalysts show hierarchical porosity, with the specific surface area, total pore volume and $\mathrm{N}$-doping content ranging from $918.9-3062.7 \mathrm{~m}^{2} \mathrm{~g}^{-1}, 1.01-2.04 \mathrm{~cm}^{3} \mathrm{~g}^{-1}$ and $1.29-15.3$ at $\%$, respectively. Interestingly, our finding suggests that the catalytic performance is not directly related to these parameters but correlates positively with the content of graphitic $\mathrm{N}$ dopants, which is the dominant contributor for impelling both the NRR and SOR. Another intriguing finding is that for both reactions, the optimal catalyst was found to be the NKC-3-800 which possesses the highest graphitic $\mathrm{N}$ content of 3.13 at\%. In addition, to gain insight into the catalytic behavior, analyses of kinetics and thermodynamics were performed, and the catalytic mechanisms were postulated. This work paves the way for the construction of biomass-derived N-doped carbon catalysts for bi- or even multi-functional applications in various organic reactions.
\end{abstract}

(c) 2020, Dalian Institute of Chemical Physics, Chinese Academy of Sciences. Published by Elsevier B.V. All rights reserved.

\section{Introduction}

Catalysis has been, and will continue to be, of paramount importance to the human society since most chemical processes involve catalysts for the manufacture of a wide range of chemicals that are indispensable to our daily life [1]. The vast majority of catalysts for the chemical production, environmental remediation, and energy conversion and storage contain metals or even precious metals as the active sites. Although these metal-based catalysts show promising catalytic activity and/or product selectivity, their commercial utility is hindered by the high cost, limited reserves, easy metal sintering and un-

\footnotetext{
* Corresponding author. E-mail: liujy@yzu.edu.cn

This work was supported by the Natural Science Foundation of the Jiangsu Higher Education Institutions of China (17KJB530011), the Jiangsu Planned Projects for Postdoctoral Research Funds (2019K093), and the Priority Academic Program Development of jiangsu Higher Education Institutions (PAPD). DOI: 10.1016/S1872-2067(20)63534-3 | http://www.sciencedirect.com/science/journal/18722067 | Chin. J. Catal., Vol. 41, No. 8, August 2020
} 
desirable metal leaching during the catalytic process [2]. Hence, it is highly desirable to find highly efficient and affordable alternatives to traditional metallic catalysts. Among the nonmetallic catalysts, emerging carbon materials [3-8] with multiple advantages of earth abundance, high stability, cost effectiveness and structural tunability at the molecular and morphological levels have raised tremendous interest in terms of both fundamental research and industrial applications, and have displayed promising applications in the oxygen reduction reaction [9], hydrogen evolution reaction [10], photocatalytic water splitting [11], $\mathrm{CO}_{2}$ reduction [12], $\mathrm{C}-\mathrm{H}$ bond activation reaction [13], acetylene hydrochlorination [14] and oxidative amidation of primary alcohols [15]. Previous studies have demonstrated that the incorporation of hereroatoms (e.g., nitrogen, boron, sulfur and phosphorus) with electro-donating or electron-withdrawing characteristics into the carbon matrix is a feasible strategy to improve the catalytic performance by creating point defects through electron modulation [2,10,16-19]. Among these alien atoms, nitrogen, the neighbor element next to carbon in the periodic table, is the most studied since it has an atomic radius similar to that of carbon but different electronegativity [5,17]. N-doping can break the chemical inertness of carbon by changing the electronic configuration, and thus the carbon structure can be turned to be highly active for catalytic applications [13,16,20-22]. Different nitrogen dopants as shown in Scheme 1 can be generated after nitrogen modification, i.e., graphitic $\mathrm{N}$ ( $\mathrm{N}$ atoms substituting for $\mathrm{C}$ atoms in a six-membered ring, also called substituted $\mathrm{N}$ or quaternary $\mathrm{N}$ ), pyridinic $\mathrm{N}$ ( $\mathrm{N}$ atoms bonded to two $\mathrm{C}$ atoms and contributing to the aromatic $\pi$ system with one p electron), pyrrolic $N$ (N atoms incorporated in a five-membered ring and contributing two p electrons to the $\pi$ system) and pyridine $\mathrm{N}$-oxide ( $\mathrm{N}$ atoms bonded with one 0 atom and two $C$ atoms) [21,23-26].

Thanks to the various research works in this area, $\mathrm{N}$-doped carbon catalysts such as carbon nanotubes [27], carbon spheres [28], graphene [29], mesoporous carbon [20] and carbon nanofibers [30] have been developed and exhibited satisfactory catalytic reaction performances. However, the wide

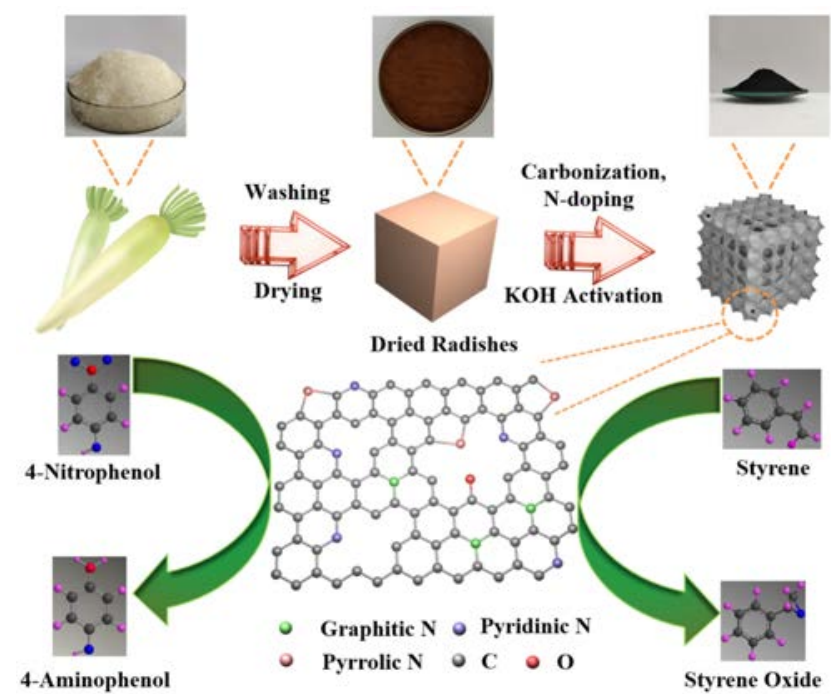

Scheme 1. Schematic illustration for the preparation process of a radish-derived NKC sample. spread and commercialization of these carbon-based catalysts are generally impeded by the harsh reaction condition, the usage of highly toxic reagent and complex or time-consuming preparation process. This is even more difficult since we are living at a time when the global energy and environmental crises pose serious challenges to the human race. As we search for solutions to these problems for a sustainable future, it is vital to get ideas from mother nature by utilizing cheap and renewable biomass as the carbon source for $\mathrm{N}$-doping. For example, Zhao et al. [31] reported that alfalfa-derived $\mathrm{N}$-doped porous carbon prepared by a pyrolysis method was active for the electrocatalytic $\mathrm{N}_{2}$ reduction reaction. The sample with a nitrogen content of 6.35 at\% presented high catalytic activity, and the experimental and theoretical calculations results suggested that the doped pyridinic $\mathrm{N}$ in the catalyst can break away from its surface to generate $\mathrm{N}$ vacancies in the carbon matrix as catalytically active sites for $\mathrm{N}_{2}$ adsorption and activation. Yao and coworkers [32] prepared a N-doped nanoporous carbon sheet derived from Typha with high surface area, pore volume and pyridinic $\mathrm{N}$ content, which achieved a much higher selectivity for $\mathrm{CO}$ in the $\mathrm{CO}_{2}$ electroreduction reaction. They found that the calcination temperature had a great influence on the porous structure and the kinds of $\mathrm{N}$ species in the catalyst. Li et al. [33] developed a dual-templating approach to prepare hierarchically macro-/meso-/microporous heteroatom-doped carbon materials using several biomass precursors. The obtained hierarchically porous nitrogen/oxygen-doped carbon catalysts showed enhanced electrocatalytic performance for the oxygen reduction reaction. Unfortunately, it is not difficult to find that the majority studies performed up to now have focused on the electrocatalytic area of these biomass-derived carbon catalysts, while their potential applications remain largely unexplored. Thus, it is quite essential to develop cost-effective and high-performance $\mathrm{N}$-doped carbon catalysts from common biomass and explore them in more catalytic fields such as organic catalysis.

Among such catalytic reactions in which metals, especially precious metals play significant catalytic roles, the NRR [34-38] and SOR [39-42] are among the most notable and important ones. 4-Nitrophenol (4-NP), which can cause severe threat to the environment and various diseases in human, is a common and bio-refractory pollutant in the chemical industry and listed as a priority toxic pollutant by the United States Environmental Protection Agency [43,44]. Of all the ways to alleviate its contamination and harm, the catalytic reduction of 4-NP to 4-aminophenol (4-AP) is the most economical way from both the environmental and industrial views since the obtained 4-AP is widely used in the production of pharmaceutical products $[37,45]$. While metals have been demonstrated to be effective for this reaction, the design of an efficient biomass-derived carbon catalyst is more appealing and still challenging. For the SOR, it is of vital importance for the production of many value-added chemicals, e.g., styrene oxide (SO), which is an important intermediate for the synthesis of plasticizers, perfumes, drugs, pharmaceuticals, etc. [40,41]. Although various metal catalyst including homogeneous and heterogeneous ones have been employed for this reaction, there have been no 
reports on developing $\mathrm{N}$-doped carbon catalyst from biomass as the precursor for the SOR.

In this study, various NKC catalysts were prepared by simultaneous $\mathrm{N}$-doping and $\mathrm{KOH}$ activation from radish as the carbon source with different urea dosage and carbonization temperature. The obtained catalysts were thoroughly characterized and employed as intriguing bifunctional catalysts for the NRR and SOR. Various reaction parameters such as reaction temperature, reaction time, catalyst dosage and amount of reactants on the catalytic performances were fully investigated to screen the optimum reaction condition and better understand the catalytic process. Graphitic N content in the carbon framework was found to be of vital importance for both reactions. A full kinetic and thermodynamic analysis was also carried out, and some important parameters including apparent rate constant, activation energy, activation enthalpy, activation entropy and Gibbs free-energy of activation were carefully calculated in order to deeply explore the reaction behavior.

\section{Experimental}

\subsection{Materials and reagents}

The radish was commercially available and purchased from the vegetable market of Hanjiang District, Yangzhou City, Jiangsu Province. Urea, KOH, hydrochloric acid, styrene, acetonitrile, tert-butyl hydroperoxide (TBHP, $65 \mathrm{wt} \%$ in water), acetone, N,N-dimethyl formamide, N,N-dimethyl acetamide and ethanol were of analytical grade, purchased from Sinopharm Chemical Reagent Co., Ltd (Shanghai, China) and used directly without further purification. Deionized (DI) water was used throughout the experiments.

\subsection{Catalyst preparation}

The radish was washed thoroughly with DI water to eliminate the impurities (dust and water soluble substances), cut into small pieces, dried at $120{ }^{\circ} \mathrm{C}$ for $12 \mathrm{~h}$, and then crushed into powders $(\sim 250 \mu \mathrm{m})$. Afterwards, the obtained carbon precursor was fully mixed with $\mathrm{KOH}$ and urea with a mass ratio of 1:1: $x(x=1,2,3)$. The mixture was then heated in a tube furnace under a nitrogen atmosphere at $130{ }^{\circ} \mathrm{C}$ for $2 \mathrm{~h}, 210^{\circ} \mathrm{C}$ for $2 \mathrm{~h}$ and finally carbonized at a temperature of $y^{\circ} \mathrm{C}(y=700$, $800,900)$ for $1 \mathrm{~h}$ at a heating rate of $5{ }^{\circ} \mathrm{C} / \mathrm{min}$. After cooling down to room temperature naturally, the sample was washed repeatedly with $2 \mathrm{M} \mathrm{HCl}$ solution and DI water, and then dried at $100{ }^{\circ} \mathrm{C}$ for $10 \mathrm{~h}$. The final product was labeled as NKC- $x-y$, in which $x$ denotes the mass ratio of urea to carbon precursor powder and $y$ denotes the carbonization temperature. The process used to prepare the NKC samples is schematically illustrated in Scheme 1. For comparison, the sample prepared without urea at $800{ }^{\circ} \mathrm{C}$ was labeled as $\mathrm{KC}-800$; the sample prepared without $\mathrm{KOH}$ at $800{ }^{\circ} \mathrm{C}$ was labeled as NC-3-800; the sample prepared without urea and $\mathrm{KOH}$ at $800{ }^{\circ} \mathrm{C}$ was labeled as C-800.

\subsection{Catalyst characterization}

The powder X-ray diffraction (XRD) analysis was performed on a D8 Advance diffractometer with $\mathrm{Cu} K_{\alpha}$ radiation. Raman spectra of the samples were obtained on a Renishaw inVia laser Raman spectrometer. The scanning electron microscopy (SEM) images and energy dispersive spectroscopy (EDS) data were obtained on a Zeiss_Supra55 field emission scanning electron microscope. Thermogravimetric (TG) analysis was conducted on a Pyris 1 thermogravimetric analyzer. The nitrogen adsorption-desorption measurements were conducted on a Quantachrome Autosorb-iQ3 sorption analyzer. The surface area was calculated by the Brunauer-Emmett-Teller (BET) method, and the pore size distribution was obtained by the Barrett-Joyner-Haleda (BJH) and the Horvath-Kawazoe (HK) methods for the mesopore and micropore analyses, respectively. The transmission electron microscopy (TEM) and high resolution TEM (HRTEM) images were obtained on a Tecnai G2 F30 S-TWIN microscope, equipped with an EDS attachment. The surface properties of the sample were investigated using the X-ray photoelectron spectroscopy (XPS, Thermo, Fisher Scientific ESCALAB 250Xi).

\subsection{Catalytic test}

The series of samples were employed as bifunctional catalysts for the NRR and SOR. For the NRR, as a representative example, $20 \mathrm{~mL}$ of $4-\mathrm{NP}$ aqueous solution $(0.1 \mathrm{mM})$ was firstly mixed with $5 \mathrm{~mL}$ of freshly prepared $\mathrm{NaBH}_{4}$ aqueous solution $(0.08 \mathrm{M})$. Thereafter, a certain amount of catalyst was added into the solution, and the progress of the reaction was consecutively monitored by recording the absorption spectra with a UV-vis spectrometer. Based on the Beer-Lambert law, the absorbance of the peaks at 400 and $300 \mathrm{~nm}$ can be used to calibrate the concentrations of 4-NP and 4-AP, respectively. In addition, for the thermodynamic and kinetic analysis, the reduction reactions were performed at $25-40{ }^{\circ} \mathrm{C}$ and with various concentrations of 4-NP and $\mathrm{NaBH}_{4}$. For the SOR, typically, styrene, solvent and catalysts were mixed in a three-necked glass flask equipped with a reflux condenser. When the desired reaction temperature was reached, TBHP as the oxidant was added under continuous stirring. The reaction mixture was sampled with an interval of $1 \mathrm{~h}$ and analyzed by gas chromatography equipped with a KB-1 column. Different reaction parameters including reaction temperature, catalyst dosage and styrene/TBHP ratio were systematically investigated.

\section{Results and discussion}

\subsection{Phase, texture and morphology}

The schematic illustration for the preparation process is shown in Scheme 1. In this study, cheap and abundant radish is used as a carbon precursor, and it can be transformed into carbon materials after high-temperature carbonization. Fig. 1 shows the representative SEM images of the radish-derived samples. It can be observed that the two samples of C-800 (Fig. 1(g) and NC-3-800 (Fig. 1(h)) without KOH activation show irregular bulk morphologies while the $\mathrm{KC}-800$ prepared with 


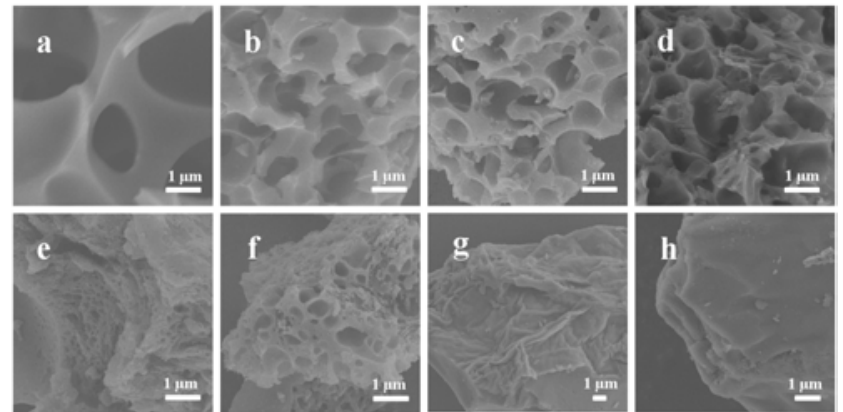

Fig. 1. Representative SEM images of the KC-800 (a), NKC-1-800 (b), NKC-2-800 (c), NKC-3-800 (d), NKC-3-700 (e), NKC-3-900 (f), C-800 (g) and NC-3-800 (h).

the introduction of $\mathrm{KOH}$ activation has large cavities (Fig. 1(a)). Interestingly, the samples (Fig. 1(b)-(f)) prepared with $\mathrm{KOH}$ activation and N-doping at the same time present honeycomb-shaped porous structures. This suggests that the simultaneous activation and doping process has a great effect on the morphologies of the samples. In addition, compared with the urea dosage, the carbonization temperature seems to have a more obvious effect of the morphology. With the increase of the carbonization temperature from $700{ }^{\circ} \mathrm{C}$ (NKC-3-700, Fig. 1(e)) to $800{ }^{\circ} \mathrm{C}$ (NKC-3-800, Fig. 1(d)), the morphology turns to be looser and the holes become larger. However, further increasing the carbonization temperature results in structure collapse in the NKC-3-900 (Fig. 1(f)). This indicates a suitable carbonization temperature of $800{ }^{\circ} \mathrm{C}$ combined with simultaneous $\mathrm{N}$-doping is more favorable for the formation of a good morphology. It is also interesting to note that in comparison with the unactivated samples, the activated ones are lighter and fluffier (Fig. S1). Of all the samples, the NKC-3-800 presents the best 3D porous carbon structure and should be given more attention. The highly porous structure of the NKC-3-800 can also be observed from the TEM image in Fig. 2(a). An enlarged view of the structure (Fig. 2(b)) shows numerous worm-like nanopores homogeneously distributed in the sample. The EDS mapping images (Fig. 2(c)-(f)) further show the homogeneous elemental distribution of $\mathrm{C}, \mathrm{N}$ and $\mathrm{O}$ in the NKC-3-800 sample.

The XRD patterns (Fig. S2) show that all the samples exhibit two weak and broad diffraction peaks at around $24.5^{\circ}$ and $43.8^{\circ}$, which can be attributed to the (002) and (100) planes of amorphous graphitic carbon, respectively. The samples with high $\mathrm{N}$-doping content (Table 1, discussed later in this study) such as NC-3-800, NKC-3-700 and NKC-3-800 show shifting of the peak of the (002) plane to higher angles as compared with the others. This is due to the increase in the interlayer attractive force due to the uneven distribution of charges induced by the high N-doping content [46]. TG analysis (Fig. S3) of the NKC-3-800 indicates that it was burned off with almost no residue content. Fig. S4 presents the Raman spectra of the samples. The two distinct peaks located at around 1350 (D band) and $1606 \mathrm{~cm}^{-1}$ (G band) of the samples can be attributed to the defected carbon and crystalline graphite, respectively [47]. Generally, the ratio of $\mathrm{D}$ band and $\mathrm{G}$ band $\left(\mathrm{I}_{\mathrm{D}} / I_{\mathrm{G}}\right)$ is used to evaluate the structure distortion [16]. It can be found that the
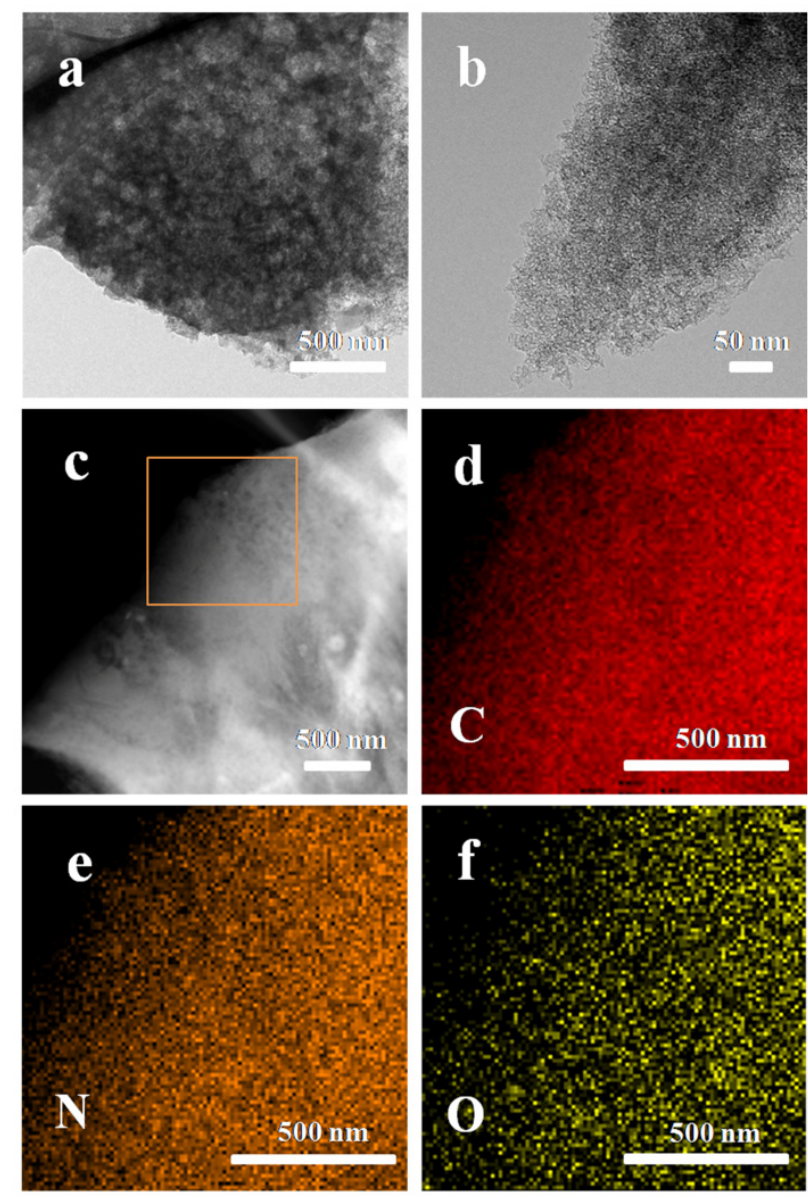

Fig. 2. TEM images $(a, b)$ and EDS elemental mapping (c-f) of the NKC-3-800.

samples with $\mathrm{N}$-doping and/or $\mathrm{KOH}$ activation show larger $I_{\mathrm{D}} / I_{\mathrm{G}}$ values than the C-800, suggesting that both the incorporation of nitrogen atoms and the $\mathrm{KOH}$ activation can induce the occurrence of structural deformation in the samples.

The XPS tests were carried out to gain more insights into the chemical environment and surface elemental compositions of the samples. As shown in Fig. S5, all the samples show the presence of $\mathrm{C}, \mathrm{N}$ and $\mathrm{O}$ elements. The nitrogen content in the samples is closely connected with the preparation conditions. The C-800 subjected to direct pyrolysis without extra N-doping shows a nitrogen content of 3.63 at $\%$, which decreases remarkably to only 0.35 at $\%$ in the $\mathrm{KC}-800$ after $\mathrm{KOH}$ activation ( $\mathrm{N}$ atoms in these two samples should come from the radish itself). This suggests that the $\mathrm{KOH}$ activation can lead to the loss of $\mathrm{N}$ atoms in the $\mathrm{N}$-doped samples due to the partial replacement of nitrogen by oxygen in the activation reaction, which has also been also observed in other reports [48,49]. After $\mathrm{N}$-doping, the NC-3-800 presents a very high $\mathrm{N}$ content of 18.7 at $\%$, while this value decreases to 11.8 at $\%$ in the NKC-3-800. With the increase of the urea usage in the carbonization process, the $\mathrm{N}$ contents in the series of NKC samples exhibit a good regularity, following the order of NKC-3-800 (11.8 at\%) > NKC-2-800 (4.50 at\%) > NKC-1-800 (1.29 at\%). As for the carbonization temperature, it can be observed that the $\mathrm{N}$ contents in the NKC-3-700, NKC-3-800 and NKC-3-900 are 15.3, 11.8, 
Table 1

The $\mathrm{N}_{2}$ adsorption-desorption and XPS analysis results of the samples.

\begin{tabular}{|c|c|c|c|c|c|c|c|c|c|c|}
\hline \multirow{2}{*}{ Sample } & \multirow{2}{*}{$S_{\text {BET }}\left(\mathrm{m}^{2} \mathrm{~g}^{-1}\right)$} & \multirow{2}{*}{$D_{\mathrm{HK}}(\mathrm{nm})$} & \multirow{2}{*}{$D_{\text {вјн }}(\mathrm{nm})$} & \multirow{2}{*}{$V_{\mathrm{t}}\left(\mathrm{cm}^{3} \mathrm{~g}^{-1}\right)$} & \multicolumn{6}{|c|}{ XPS results } \\
\hline & & & & & $\mathrm{C}$ & $\mathrm{N}$ & $\mathrm{N}-\mathrm{C}^{\mathrm{a}}$ & $\mathrm{N}-6^{\mathrm{b}}$ & $\mathrm{N}-5^{\mathrm{c}}$ & $\mathrm{N}-\mathrm{O}^{\mathrm{d}}$ \\
\hline NKC-3-800 & 2163.3 & 0.51 & 2.00 & 1.88 & 82.7 & 11.8 & 3.13 & 3.58 & 3.96 & 1.11 \\
\hline NKC-2-800 & 3062.7 & 0.58 & 2.12 & 2.04 & 88.0 & 4.50 & 1.26 & 0.95 & 1.71 & 0.58 \\
\hline NKC-1-800 & 2715.5 & 0.57 & 2.12 & 1.63 & 92.5 & 1.29 & 0.62 & - & 0.67 & - \\
\hline KC- 800 & 2068.7 & 0.48 & 2.00 & 1.12 & 93.3 & 0.35 & 0.16 & - & 0.19 & - \\
\hline NKC-3-700 & 971.0 & 0.50 & 2.12 & 1.01 & 78.7 & 15.3 & 2.50 & 4.95 & 6.87 & 1.01 \\
\hline NKC-3-900 & 918.9 & 0.64 & 2.12 & 1.01 & 87.0 & 9.61 & 2.65 & 3.28 & 2.91 & 0.77 \\
\hline NC-3-800 & 153.8 & 0.50 & 2.25 & 0.19 & 76.4 & 18.7 & 2.78 & 8.01 & 6.54 & 1.35 \\
\hline $\mathrm{C}-800$ & 426.1 & 0.50 & 2.00 & 0.47 & 88.4 & 3.63 & 0.93 & 1.04 & 1.42 & 0.24 \\
\hline
\end{tabular}

${ }^{a}$ Graphitic N; byridinic $\mathrm{N} ;{ }^{c}$ pyrrolic N; ${ }^{\text {d }}$ pyridine $\mathrm{N}$-oxide.

and 9.61 at\%, respectively. This indicates that the higher carbonization temperature can cause a decrease of the $\mathrm{N}$ content in the sample. For the high-resolution XPS C1s spectra displayed in Fig. 3(b, d) and Fig. S6(a, c), they can be deconvoluted into four peaks, which can be ascribed to $\mathrm{C}=\mathrm{C}(\sim 284.7 \mathrm{eV}), \mathrm{C}=\mathrm{N}$ $(\sim 285.7 \mathrm{eV}), \mathrm{N}-\mathrm{C} / \mathrm{C}=\mathrm{O}(\sim 288.2 \mathrm{eV})$ and $\mathrm{O}-\mathrm{C}=\mathrm{O}(\sim 290.7 \mathrm{eV})$ [50]. The high-resolution XPS N 1s spectra of the samples in Fig. 3(a, c) and Fig. S6(b, d) can be deconvoluted into a maximum of four peaks, corresponding to the presence of pyridinic $\mathrm{N}$ $(\sim 398.5 \mathrm{eV})$, pyrrolic $\mathrm{N}(\sim 400.2 \mathrm{eV})$, graphitic $\mathrm{N}(\sim 401.6 \mathrm{eV})$ and pyridine $\mathrm{N}$-oxide $(\sim 405.7 \mathrm{eV})$ groups $[16,23]$. The detailed contents of $\mathrm{N}$ species in the samples are listed in Table 1.

The porous textures of the samples were characterized by the $\mathrm{N}_{2}$ adsorption-desorption experiments, and the results are shown in Fig. 4 and Table 1. For the samples activated with $\mathrm{KOH}$, the $\mathrm{N}_{2}$ uptake at a low relative pressure $\left(P / P_{0}<0.01\right)$ displays an obvious vertical rise (Fig. 4(a)), suggesting the existence of micropores. In addition, the hysteresis loop with a $\mathrm{H} 4$ character $\left(0.45<P / P_{0}<0.99\right)$ is generated by capillary condensation in slit-shaped mesopores [51]. As shown in Table 1, the $\mathrm{KOH}$ activation process causes significant enhancement of the specific surface area (SSA) for all activated samples, while the samples subjected to only $\mathrm{N}$-doping without any activation show small SSA values. Especially, the samples activated at 800 ${ }^{\circ} \mathrm{C}$ show SSA values higher than $2000 \mathrm{~m}^{2} \mathrm{~g}^{-1}$, indicating that this temperature is beneficial for the deep impregnation of molten $\mathrm{KOH}$ [52]. This finding is also in accordance with that of the SEM analysis as indicated above. Among the samples, the NKC-2-800 shows the highest SSA of $3062.7 \mathrm{~m}^{2} \mathrm{~g}^{-1}$, which is 18.9 and 6.2 times higher than those for the unactivated samples of NC-3-800 and C-800, respectively. In addition, the activated samples show the total pore volume higher than $1.00 \mathrm{~cm}^{3}$ $\mathrm{g}^{-1}$, and the highest value is also obtained in the NKC-2-800 $\left(2.04 \mathrm{~cm}^{3} \mathrm{~g}^{-1}\right)$. The pore size distributions (PSD) (Fig. 4(b)) show that the samples exhibit hierarchical porous structures, with micropore PSD centered at ca. $0.5 \mathrm{~nm}$ and mesopore PSD at ca. $2.1 \mathrm{~nm}$, respectively. The hierarchical porosity coupled with plentiful pore channels, high SSA and pore volume is expected to boost the catalytic performance by facilitating the mass transportation of reactants and their easy accessibility to

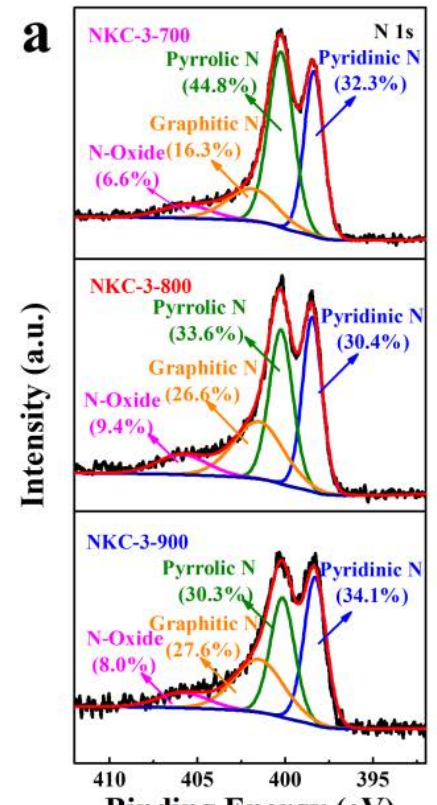

Binding Energy (eV)
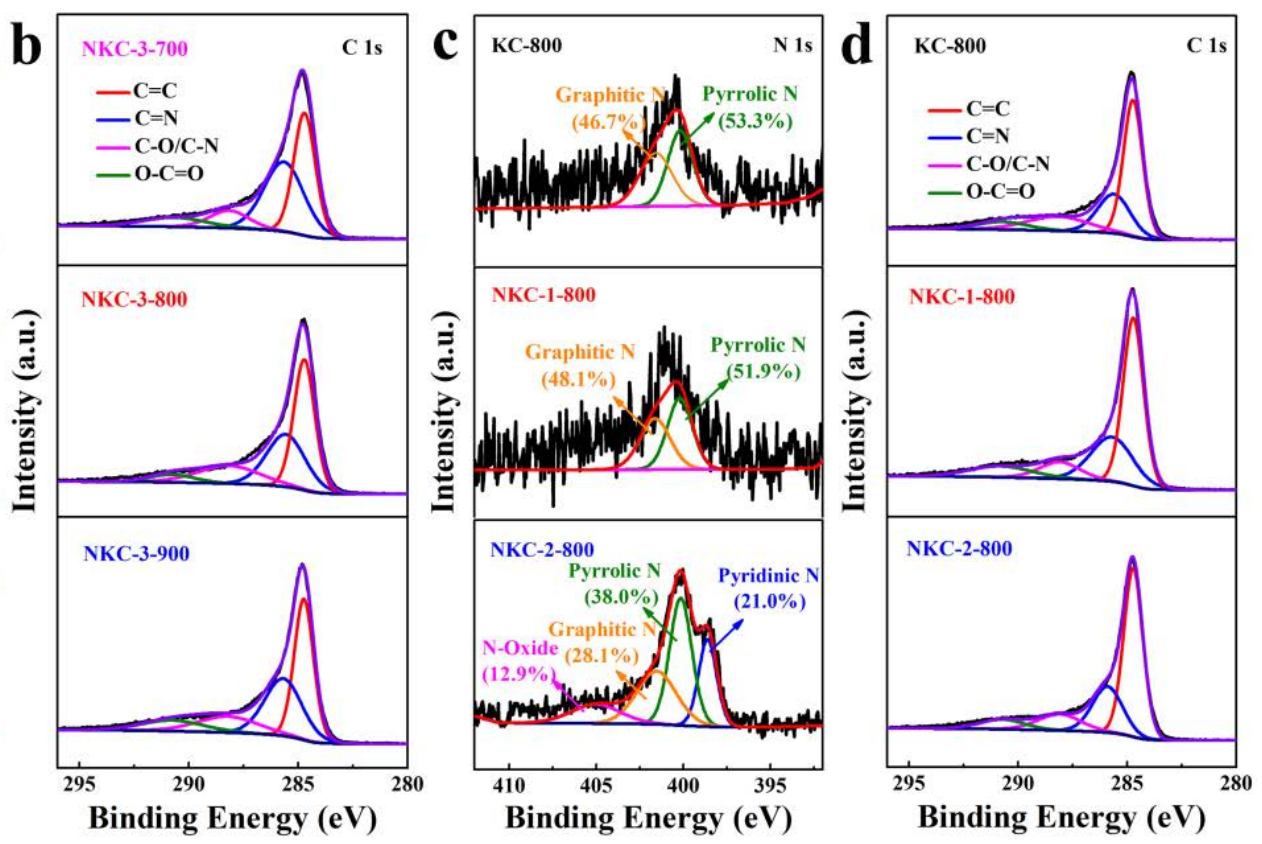

Fig. 3. High-resolution XPS N $1 s(\mathrm{a}, \mathrm{c})$ and C $1 s$ (b, d) spectra of the samples. 

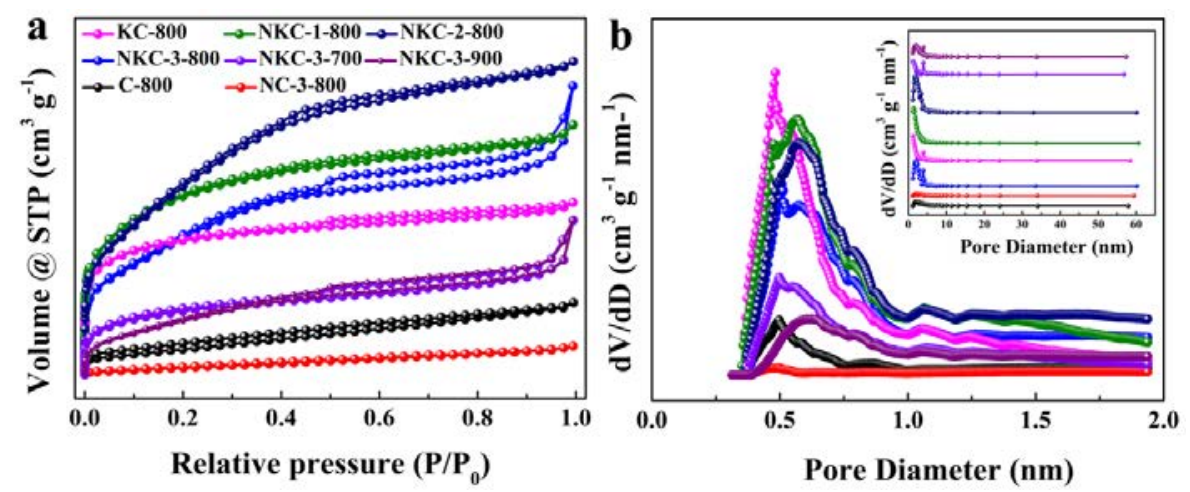

Fig. 4. (a) $\mathrm{N}_{2}$ adsorption-desorption isotherms; (b) pore size distributions of $\mathrm{HK}$ and BJH (inset).

the active sites.

\subsection{Catalytic test for the NRR}

The series of radish-derived carbon catalysts were firstly employed in the NRR with the presence of $\mathrm{NaBH}_{4}$ as the reductant. As shown in Fig. 5(a), after the addition of $\mathrm{NaBH}_{4}$ solution, the absorption peak at $317 \mathrm{~nm}$ corresponding to the 4-NP aqueous solution shifted to $400 \mathrm{~nm}$ due to the formation of 4-Nitrophenolate ions. Simultaneously, the solution color changed from light yellow to bright yellow (Fig. 5(a), inset). In the absence of a catalyst, the peak intensity was maintained, indicating this reaction can't proceed without catalysts due to the high kinetic barrier between the two negatively charged reactants $[34,38]$. Upon the addition of an efficient catalyst such as NKC-3-800, the absorption peak at $400 \mathrm{~nm}$ decreased quickly and a new absorption peak at $300 \mathrm{~nm}$ attributed to 4-AP was established at the same time and increased gradually in peak intensity. After reaction of $12 \mathrm{~min}$, the peak at $400 \mathrm{~nm}$ vanished and the solution became colorless. Surprisingly, the
C-800, KC-800 and NC-800 are incompetent to drive this reaction, showing almost no catalytic activity (Fig. S7). The slight decrease in peak intensity at $400 \mathrm{~nm}$ of these samples should be due to the adsorption effect. This suggests that both the $\mathrm{N}$-doping and $\mathrm{KOH}$ activation play important roles in the preparation of efficient carbon catalysts for the NRR.

Generally, the doping of $\mathrm{N}$ atoms in the carbon framework can trigger the charge modulation, which renders the carbon atoms adjacent to the $\mathrm{N}$ dopants with high electropositivity for the counterbalance of the strong electronic affinity of $\mathrm{N}$ atoms $[17,23]$. It can be inferred that the negatively charged 4-Nitrophenolate and $\mathrm{BH}_{4}$ - ions can be readily adsorbed on the catalyst surface via electrostatic attraction in the N-doped carbon catalysts [53]. This can be verified by the adsorption experiments of the 4-NP solution (Fig. 5(c)), in which the KC-800 and NKC-3-800 with similar SSA (2068.7 vs. $2163.3 \mathrm{~m}^{2} \mathrm{~g}^{-1}$ ) also shows similar adsorption ability of 4-NP. However, as indicated above, the KC-800 shows very little adsorption of 4-nitrophenolate ions (Fig. S7). The KOH activation can endow the carbon catalyst with advantages of high surface area and
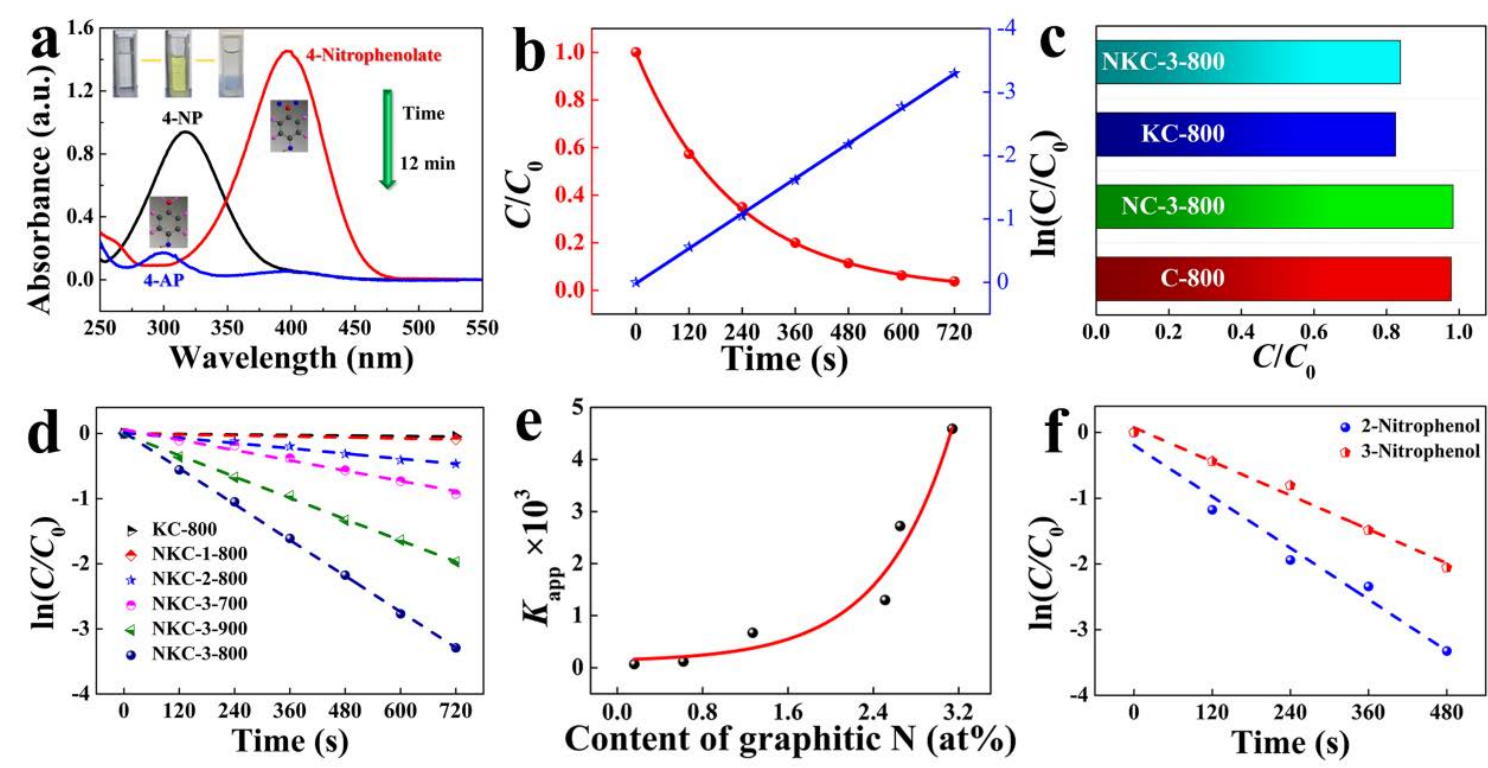

Fig. 5. (a) The evolution of UV-vis absorption spectra for the NRR with the NKC-3-800 as the catalyst (inset shows the color change during the process); (b) $C / C_{0}$ and $\ln \left(C / C_{0}\right)$ versus reaction time; (c) The adsorption of 4-NP solution with different catalysts within a duration of 12 min; (d) Catalytic

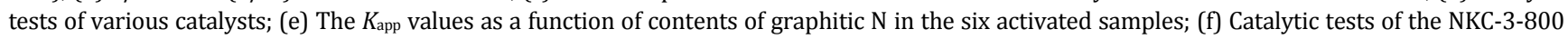
for the reduction of 2-NP and 3-NP. Reaction condition: $0.1 \mathrm{mM}$ substrate, $0.08 \mathrm{M} \mathrm{NaBH}_{4}$ solution, $1 \mathrm{mg}$ catalyst, $25^{\circ} \mathrm{C}$. 
large pore volume (Table 1), which can provide abundant active sites and facilitate the molecular diffusion within the channels. The importance of $\mathrm{KOH}$ activation can be reflected from the reaction results of NKC-3-800 and NC-3-800 (Fig. S7). Although the latter has a higher N-doping content, it presents a negligible catalytic activity when compared with the former. What's more, it's interesting to find that the samples exhibit quite different hydrophilcity. As shown in Fig. S8, the samples with $\mathrm{KOH}$ activation (KC-800 and NKC-3-800) present much better dispersability in water than the unactivated samples (C-800 and NC-3-800). The good hydrophilcity of the catalysts can assist in the transportation of 4-nitrophenolate and $\mathrm{BH}_{4}^{-}$ ions in the aqueous solution to the active sites, promoting the mass utilizing efficiency of the catalysts. To sum up, both the $\mathrm{N}$-doping and $\mathrm{KOH}$ activation are indispensable for the construction of a high-performance NRR catalyst.

Fig. 5(b) shows a linear correlation between $\ln \left(C / C_{0}\right)$ and the reaction time $t$ ( $C$ and $C_{0}$ are the 4-NP concentrations at time $t$ and 0 , respectively), suggesting that the reaction adopts the pseudo-first-order kinetics [34]. The apparent rate constant (Kapp) determined from the slope is $4.59 \times 10^{-3} \mathrm{~s}^{-1}$ for the NKC-3-800. In addition, all the other NKC catalysts were also tested under the same reaction conditions (Fig. 5(d)), resulting in the Kapp values of $1.23 \times 10^{-4} \mathrm{~s}^{-1}$ (NKC-1-800), $6.66 \times 10^{-4} \mathrm{~s}^{-1}$ (NKC-2-800), $1.31 \times 10^{-3} \mathrm{~s}^{-1}$ (NKC-3-700) and $2.72 \times 10^{-3} \mathrm{~s}^{-1}$ (NKC-3-900). Obviously, the NKC-3-800 shows the best catalytic performance. Interestingly, although a high SSA is favorable for heterogeneous catalytic reaction, there is no evidence to suggest that the NRR performance depends on these data (Table 1) since the NKC-2-800 with the highest SSA does not show the best activity. Hence, there must be some inner difference in the series of catalysts, which produces this enormous disparity on the NRR performance. As shown in Fig. 5(e), the catalytic activity is irrespective of the total $\mathrm{N}$ content but correlates positively with the graphitic $\mathrm{N}$ content. And the variation of $K_{\text {app }}$ with respect to the content of graphitic $\mathrm{N}$ can be well described by the exponential relationship. The importance of graphitic $\mathrm{N}$ was also found in a previous study where the researchers reported that the graphitic $\mathrm{N}$ with the lowest adsorption energy was the key determined for impelling the NRR rather than the amount of $\mathrm{N}$ atoms in the $\mathrm{N}$-doped graphene catalysts [54]. Furthermore, the reduction of other two isomeric nitrophenols, i.e., 2-NP and 3-NP were tested as well under the similar reaction conditions with that of 4-NP. To our delight, the NKC-3-800 is also effective for the reduction of these two isomers (Fig. 5(f) and S9), suggesting its generality in the nitrophenols reduction reactions.

The catalytic efficiency is further interpreted by the turnover frequency (TOF) value, defined as the molar amount of 4-NP that $1 \mathrm{mg}$ of a catalyst can convert into 4-AP per unit time for the comparison of our result with the literature reports. Excitingly, the TOF value of the NKC-3-800 catalyst is calculated to be $1.67 \times 10^{-4} \mathrm{mmol} \mathrm{mg}^{-1} \mathrm{~min}^{-1}$. This value is comparable to some of the precious metal-based catalysts such as $\mathrm{Ag} /$ carbon nanofibers $\left(4.50 \times 10^{-4} \mathrm{mmol} \mathrm{mg}^{-1} \mathrm{~min}^{-1}\right)$ [55], Au/graphene hydrogel $\left(2.33 \times 10^{-4} \mathrm{mmol}_{\mathrm{mg}^{-1}} \mathrm{~min}^{-1}\right)$ [56] and Pt1Au1-PDA/RGO (1.50 × 10-4 $\left.\mathrm{mmol} \mathrm{mg}^{-1} \mathrm{~min}^{-1}\right)$ [57], and is much higher than the $\mathrm{N}$-doped graphene $\left(6.05 \times 10^{-5} \mathrm{mmol}\right.$ $\left.\mathrm{mg}^{-1} \mathrm{~min}^{-1}\right)$ [58] and 3D N-doped graphene foams (7.41 $\times 10^{-5}$ mmol mg-1 $\mathrm{min}^{-1}$ ) [16].

Cycling stability is also a key factor for the actual application of a catalyst. Herein, the NKC-3-800 demonstrates a good catalytic stability without obvious loss in catalytic activity during

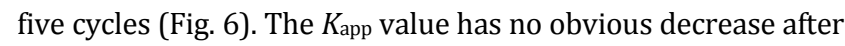
the cycling experiments. All these results demonstrate that the NKC-3-800 catalyst is a highly efficient and robust catalyst, making it a promising candidate catalyst for the NRR and beyond.

For a better understanding of the NRR catalyzed by these $\mathrm{N}$-doped porous catalysts, the NRRs were performed at various reaction conditions in the presence of the NKC-3-800 as the catalyst. Firstly, the effect of reaction temperature on the catalytic performance was explored, and the results were shown in Fig. 7(a, b). It is easy to understand that the higher reaction temperature favors a faster completion of the reaction, and hence a larger $K_{\text {app }}$ value can be expected. With the help of these $K_{\text {app }}$ vlues, we can calculate the activation energy $\left(E_{\mathrm{A}}\right)$ using the Arrhenius equation:

$$
\ln K_{\mathrm{app}}=\ln A-\frac{E_{\mathrm{A}}}{\mathrm{RT}}
$$

where $R$ is the molar gas constant, $T$ is the reaction temperature, and $A$ is the pre-exponential factor.

The activation enthalpy $(\Delta H)$ and activation entropy $(\Delta S)$ can be calculated using the Eyring equation:

$$
\ln \left(\frac{K_{\text {app }}}{\mathrm{T}}\right)=-\frac{\Delta H}{\mathrm{RT}}+\ln \left(\frac{\mathrm{k}_{\mathrm{B}}}{\mathrm{h}}\right)+\frac{\Delta \mathrm{S}}{\mathrm{R}}
$$

where $k_{\mathrm{B}}$ is the Boltzmann constant and $h$ is the Planck constant.
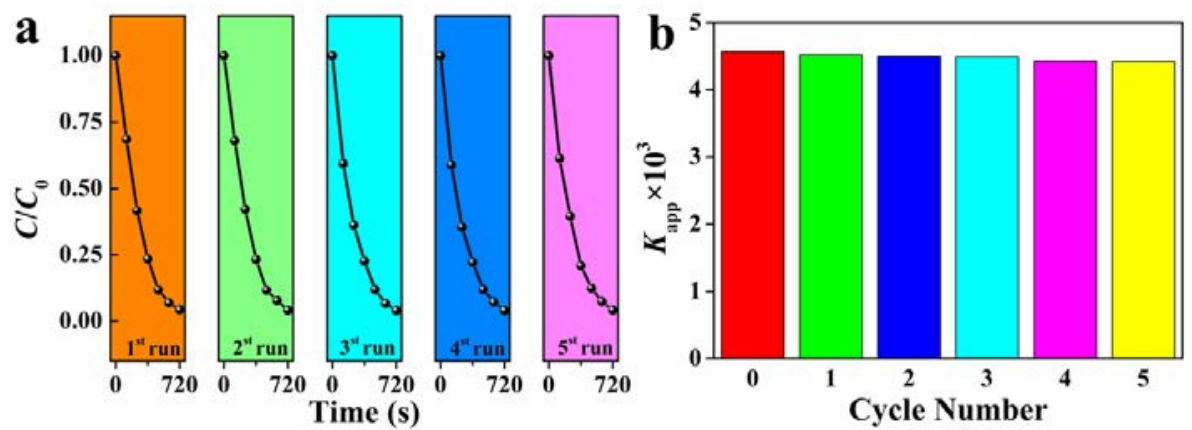

Fig. 6. (a) Recycling performance of the NKC-3-800 for the NRR. 

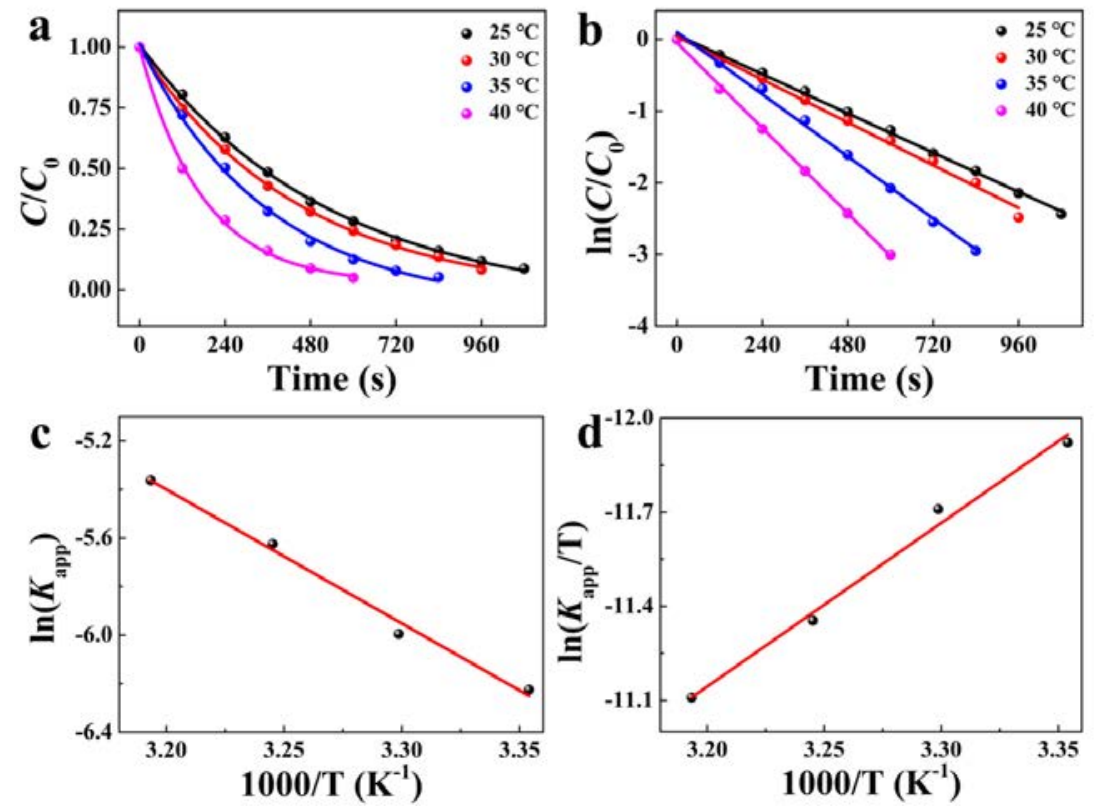

Fig. 7. $\left(C / C_{0}\right)(a)$ and $\ln \left(C / C_{0}\right)(b)$ versus reaction time; Arrhenius plot (c) and Eyring plot (d) for the NRRs at different reaction temperatures with the NKC-3-800 as the catalyst. Reaction conditions: $0.1 \mathrm{mM} 4-\mathrm{NP}, 0.08 \mathrm{M} \mathrm{NaBH}_{4}$ solution, $0.5 \mathrm{mg}$ catalyst.

Then the Gibbs free-energy of activation $(\Delta G)$ can be calculated as the following:

$$
\Delta G=\Delta H-T \Delta S
$$

The thermodynamics parameters for the NRR over the NKC-3-800 catalyst were listed in Table 2 . From the slope of the linear fitting of $\ln K_{\text {app }}$ versus $1000 / T$ (Fig. 7 (c)), the $E_{\mathrm{A}}$ value was calculated to be $45.9 \mathrm{~kJ} \mathrm{~mol}^{-1}$, which is similar with those of the reports such as $\mathrm{Pd} /$ spherical polyelectrolyte brushes (44.0 kJ mol-1) [59], the $18.0 \mathrm{~nm} \mathrm{Cu}$ polyhedrons (47.6 kJ $\mathrm{mol}^{-1}$ ) [60] and the 3D N-doped graphene foams (44.3 $\left.\mathrm{kJ} \mathrm{mol}^{-1}\right)$ [16]. From the slope and intercept of the linear fitting of $\ln \left(K_{\text {app }} / T\right.$ ) versus $1000 / T$ (Fig. $\left.7(\mathrm{~d})\right)$, the $\Delta H$ and $\Delta S$ values were calculated to be $43.4 \mathrm{~kJ} \mathrm{~mol}^{-1}$ and $-151.4 \mathrm{~J} \mathrm{~mol}^{-1} \mathrm{~K}^{-1}$, respectively. The $\Delta G$ value was increased from $88.5 \mathrm{~kJ} \mathrm{~mol}^{-1}$ at $298.15 \mathrm{~K}$ to $90.8 \mathrm{~kJ} \mathrm{~mol}^{-1}$ at $313.15 \mathrm{~K}$.

Fig. 8(a-c) shows the effect of dosage of the NKC-3-800 on the NRR performance. With the increase of the catalyst dosage from 0.5 to $1.5 \mathrm{mg}$, the reduction time needed was shortened from 18 to $8 \mathrm{~min}$ due to more active sites provided by the catalyst. Further increasing the catalyst dosage to $2.0 \mathrm{mg}$ did not help the reduction of reduction time, but can obtain a higher $K_{\text {app }}$ value. The effects of concentration of 4-NP and $\mathrm{NaBH}_{4}$ on the catalytic performance were also investigated, and the results were presented in Fig. 8(d-f) and Fig. 9(g-i). respectively.

Table 2

Thermodynamic parameters for the NRR over the NKC-3-800 catalyst a.

\begin{tabular}{lcccc}
\hline$T\left({ }^{\circ} \mathrm{C}\right)$ & $\begin{array}{c}E_{\mathrm{A}} \\
\left(\mathrm{kJ} \mathrm{mol}^{-1}\right)\end{array}$ & $\begin{array}{c}\Delta H \\
\left(\mathrm{~kJ} \mathrm{~mol}^{-1}\right)\end{array}$ & $\begin{array}{c}\Delta S \\
\left(\mathrm{~J} \mathrm{~mol}^{-1} \mathrm{~K}^{-1}\right)\end{array}$ & $\begin{array}{c}\Delta G \\
\left(\mathrm{~kJ} \mathrm{~mol}^{-1}\right)\end{array}$ \\
\hline 25 & & & & 88.5 \\
30 & 45.9 & 43.4 & -151.4 & 89.3 \\
35 & & & 90.0 \\
40 & & & 90.8 \\
\hline \multicolumn{2}{l}{$\begin{array}{l}\text { a Reaction conditions: } \\
\text { catalyst. }\end{array}$}
\end{tabular}

As observed, the $K_{\text {app }}$ value decreases firstly and then levels off with the increase of the 4-NP concentration at a fixed $\mathrm{NaBH}_{4}$ concentration. On the contrary, as the $\mathrm{NaBH}_{4}$ concentration increases while keeping the 4-NP concentration constant, the $K_{\text {app }}$ value increases initially and then remains at a certain level. These results suggest that there exists competitive adsorption on the catalyst surface between the 4-nitrophenolate and $\mathrm{BH}_{4}{ }^{-}$ ions, and the Langmuir-Hinshelwood mechanism should apply to the NRR catalyzed by the $\mathrm{N}$-doped porous carbon in this study.

The reaction kinetics can be described as the following:

$$
-\frac{d c_{4-\mathrm{NP}}}{d t}=K_{\mathrm{app}} C_{4-\mathrm{NP}}=k S \theta_{4-\mathrm{NP}} \theta_{\mathrm{BH}_{4}^{-}}
$$

where $S$ is the surface of catalyst, $k$ is the intrinsic rate constant, and $\theta_{4-\mathrm{NP}}$ and $\theta_{\mathrm{BH}_{4}^{-}}$are the surface coverage of 4-nitrophenolate and $\mathrm{BH}_{4}^{-}$respectively. In this equation, the surface coverage can be described by the Langmuir-Freundlich model:

$$
\theta_{\mathrm{a}}=\frac{\left(K_{\mathrm{a}} C_{\mathrm{a}}\right)^{n_{\mathrm{a}}}}{1+\sum_{\mathrm{b}=1}^{\mathrm{N}}\left(K_{\mathrm{b}} C_{\mathrm{b}}\right)}
$$

where $K_{\mathrm{a}}$ is the adsorption constant of component $a$, and $n_{\mathrm{a}}$ is the Freundlich exponent.

Thus, $K_{\text {app }}$ can be obtained as follows:

$$
K_{\text {app }}=\frac{k S K_{4-\mathrm{NP}}{ }^{n} C_{4-\mathrm{NP}}{ }^{n-1}\left(K_{\mathrm{BH}_{4}^{-}} C_{\mathrm{BH}_{4}^{-}}\right)^{m}}{\left(1+\left(K_{4-\mathrm{NP}} C_{4-\mathrm{NP}}\right)^{n}+\left(K_{\mathrm{BH}_{4}^{-}} C_{\mathrm{BH}_{4}^{-}}\right)^{m}\right)^{2}}
$$

The parameters in Eq. (6) can be obtained by the fitting of the kinetic data in Fig. 8(d-i), and finally we can get

$$
K_{\text {app }}=\frac{0.0034 C_{4-\mathrm{NP}}^{-0.49} C_{\mathrm{BH}_{4}^{-}}^{1.05}}{\left(1+75 C_{4-\mathrm{NP}}^{0.51}+20{C_{\mathrm{BH}}^{-}}_{4}^{1.05}\right)^{2}}
$$

A favorable consistency, as displayed in Fig. 9(a), exists between the calculated $K_{\text {app }}$ values and the experimental ones. In 

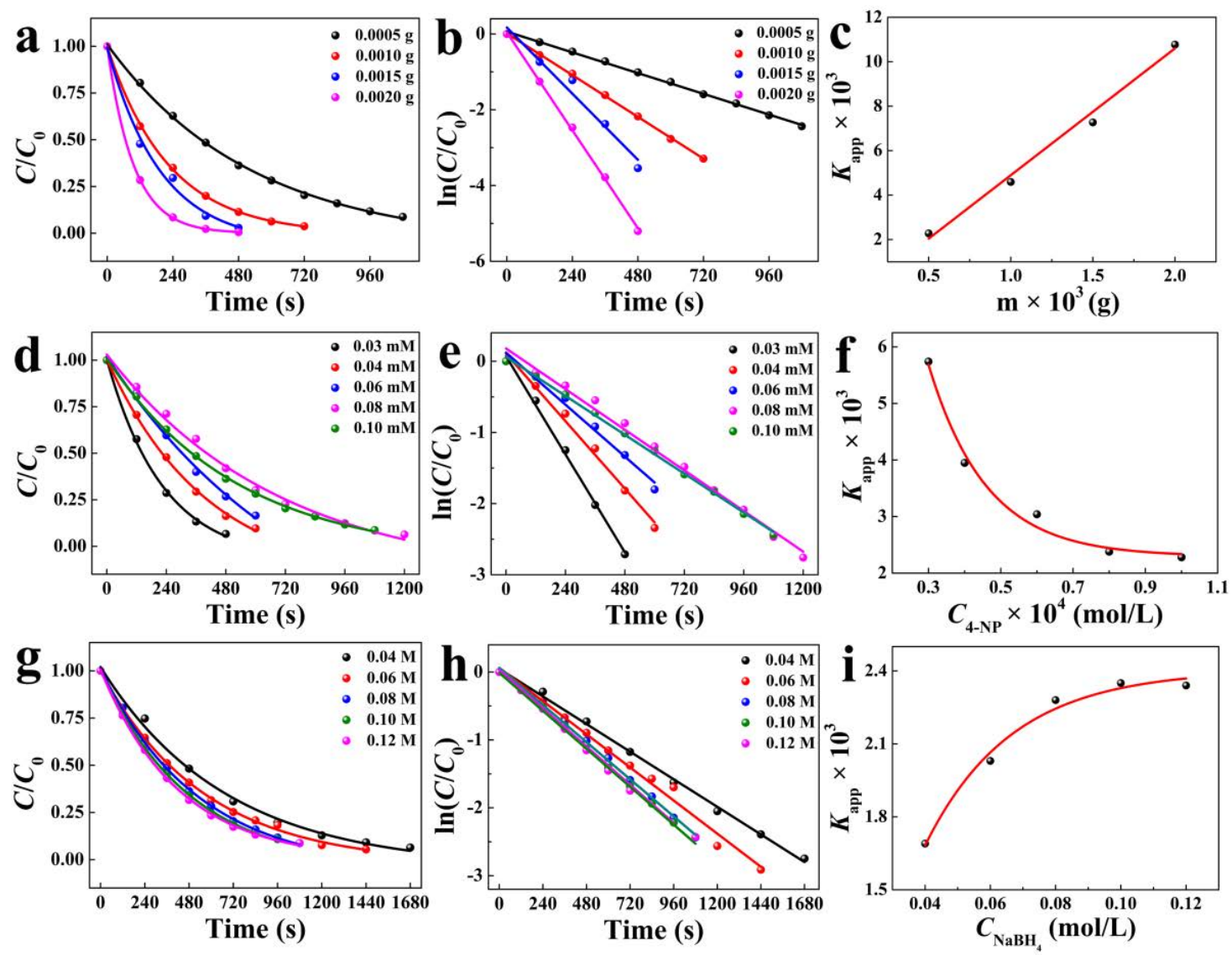

Fig. 8. Catalytic results for the NRR using the NKC-3-800 conducted with different catalyst dosage (a-c), and various concentrations of 4-NP (d-f) and $\mathrm{NaBH}_{4}$ solution (g-i). These reactions were performed by changing one parameter while keeping the other parameters unchanged.
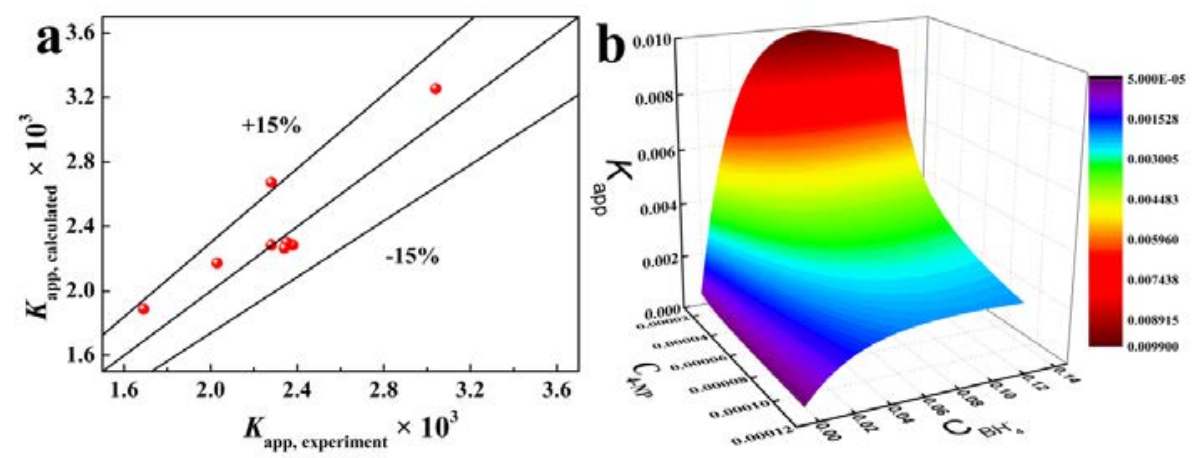

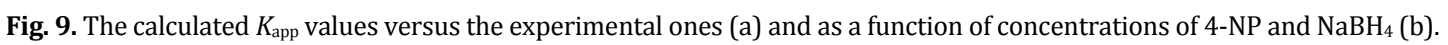

addition, Fig. 9(b) shows a 3D plotting of the calculated model

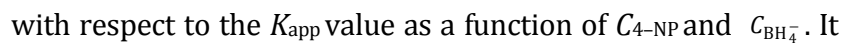
should be noted that the $K_{4-\mathrm{NP}}$ value is calculated to be 4748.9 $\mathrm{L} \cdot \mathrm{mol}^{-1}$, which is remarkably larger than the $K_{\mathrm{BH}_{4}^{-}}$value $(17.3$ $\left.\mathrm{L} \cdot \mathrm{mol}^{-1}\right)$. This indicates the stronger adsorption of 4-nitrophenolate than that of $\mathrm{BH}_{4}^{-}$on the catalyst, further demonstrating the competitive adsorption between the substrate and the reductant. As indicated above, the charge modulation within the framework of the $\mathrm{N}$-doped porous carbon is beneficial for the adsorption of the 4-nitrophenolate and $\mathrm{BH}_{4}^{-}$ ions and is expected to facilitate the electron relaying process from the donor to the acceptor. The two reactants were firstly adsorbed on the catalyst surface in a fast and reversible way as postulated by the Langmuir-Hinshelwood model. Then, the surface activated hydrogen species from the cleavage of the $\mathrm{B}-\mathrm{H}$ bond will be taken up by the 4-nitrophenolate, which is the rate-determining step for the NRR. The generated 4-AP formed on the catalyst surface then diffuses into the reactive solution.

\subsection{Catalytic test for the SOR}

Furthermore, the radish-derived carbon catalysts were employed for the SOR with TBHP as the oxidant. For all the reactions, SO and benzaldehyde were detected to be the main products along with little phenylacetaldehyde, benzoic acid, and 1-phenyl-1, 2-ethanediol as the by-products. As shown in 
Table 3

Reaction results of various catalysts for the SOR a

\begin{tabular}{lccccc}
\hline Catalyst & $\begin{array}{c}\text { Catalyst } \\
\text { dosage (mg) }\end{array}$ & $\begin{array}{c}\text { Styrene/TBHP } \\
\text { ratio }\end{array}$ & $\begin{array}{c}\text { Styrene } \\
\text { conv. (\%) }\end{array}$ & $\begin{array}{c}\text { SO sel. } \\
(\%)\end{array}$ & $\begin{array}{c}\text { SO yield } \\
(\%)\end{array}$ \\
\hline C-800 & 20 & $1: 3$ & 27.2 & 60.0 & 16.3 \\
NC-3-800 & 20 & $1: 3$ & 28.4 & 49.1 & 13.9 \\
KC-800 & 20 & $1: 3$ & 29.9 & 58.9 & 17.6 \\
NKC-1-800 & 20 & $1: 3$ & 34.2 & 70.6 & 24.1 \\
NKC-2-800 & 20 & $1: 3$ & 41.4 & 80.8 & 33.4 \\
NKC-3-700 & 20 & $1: 3$ & 51.0 & 76.5 & 39.0 \\
NKC-3-900 & 20 & $1: 3$ & 77.8 & 65.3 & 50.8 \\
NKC-3-800 & 20 & $1: 3$ & 83.5 & 76.7 & 64.0 \\
NKC-3-800 & 15 & $1: 3$ & 71.8 & 67.7 & 48.6 \\
NKC-3-800 & 25 & $1: 3$ & 84.2 & 68.4 & 57.6 \\
NKC-3-800 & 30 & $1: 3$ & 92.9 & 64.6 & 60.0 \\
NKC-3-800 & 20 & $1: 1$ & 50.4 & 70.9 & 35.7 \\
NKC-3-800 & 20 & $1: 2$ & 69.6 & 71.1 & 49.5 \\
NKC-3-800 & 20 & $1: 4$ & 83.8 & 60.0 & 50.3 \\
\hline
\end{tabular}

a Reaction conditions: $15 \mathrm{mmol}$ styrene, $16 \mathrm{ml}$ acetonitrile, $8 \mathrm{~h}, 80^{\circ} \mathrm{C}$.

Table 3, the C-800, KC-800 and NC-3-800 show the styrene conversion lower than $30 \%$ and the selectivity of SO lower than $60 \%$, while the NKC-3-800 presents a notably better catalytic performance with a styrene conversion of $83.5 \%$ and a selectivity of $76.7 \%$ to SO. The yield of SO for the NKC-3-800 is 2.93, 2.64 and 3.60 times higher than those for the C-800, KC-800 and NC-3-800, respectively. Encouragingly, this yield value of $64.0 \%$ is higher than the previously reported values for metal or even precious metal catalysts under similar reaction conditions, such as $\mathrm{Ce}_{0.95} \mathrm{Zr}_{0.05} \mathrm{O}_{2}$ (22.0\%) [61], $\mathrm{Au} / \mathrm{CaO}(\mathrm{HDP})$ (32.9\%) [62] and $\mathrm{Au} / \mathrm{Fe}_{3} \mathrm{O}_{4}$ (54.9\%) [63]. These results indicate that the NKC-3-800 with both $\mathrm{N}$-doping and $\mathrm{KOH}$ activa- tion simultaneously shows excellent catalytic performance not only in NRR but also SOR.

Obviously, among the series of NKC catalysts, the NKC-3-800 shows the best catalytic performance. Another similar finding with that of the NRR as stated above is that the SOR performance is also not decide by the total $\mathrm{N}$ densities but is highly associated with the N-doping species (graphitic N). As shown in Fig. 10(d), the more $\mathrm{N}$ there was at graphitic sites in the catalyst, the higher the yield of SO. These results show the important role of graphitic $\mathrm{N}$ for driving the SOR. This finding was also reported by Gao et al. [13] in the oxidation of ethylbenzene in the aqueous phase. In this work, they demonstrated that the graphitic-type dopant in the N-doped graphene can induce high charge and spin density at the adjacent ortho carbon, which is critical for the activation of the $\mathrm{C}-\mathrm{H}$ bond by promoting the generation of reactive oxygen species. Moreover, various reaction parameters such as the choice of solvent, reaction temperature, catalyst amount and molar ratio of styrene/TBHP on the SOR performances catalyzed by the NKC-3-800 were systematically investigated to gain deep insight into the reaction, and the results were shown in Table 3 and Table S1. An optimal reaction condition can be obtained from these experiments and described as the following: acetonitrile as the solvent, catalyst amount of $20 \mathrm{mg}$, reaction temperature of $80^{\circ} \mathrm{C}$, and molar ratio of styrene/TBHP of 1:3.

Kinetics studies also show that pseudo-first-order kinetics can be well applied for the SOR with the NKC-3-800 as the catalyst at different reaction temperatures (Fig. 10a-c). The apparent rate constant $\left(K_{\mathrm{app}}\right.$ ) values were $0.098,0.127,0.205$ and $0.283 \mathrm{~h}^{-1}$ for the SORs at $60,70,80$ and $90^{\circ} \mathrm{C}$, respectively. With the help of the Eq. (1) and Eq. (2), the thermodynamic parameters $E_{\mathrm{A}}, \Delta \mathrm{H}$ and $\Delta \mathrm{S}$ were calculated to be $36.8 \mathrm{~kJ} \mathrm{~mol}^{-1}$,

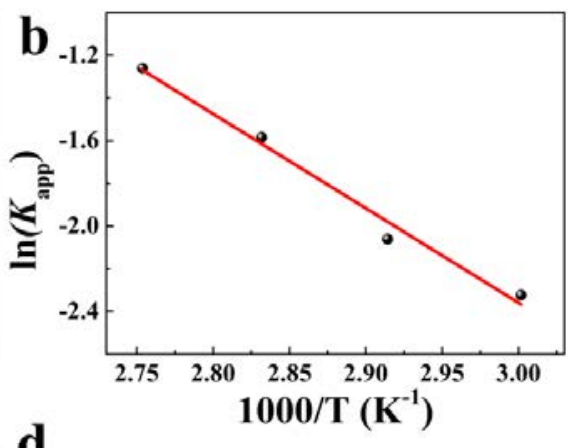

d

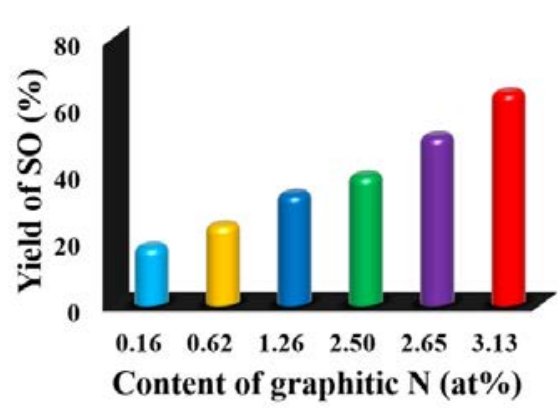

Fig. 10. $\ln \left(C / C_{0}\right)$ (a) and $\left(C / C_{0}\right)$ (a, inset) versus reaction duration of $6 \mathrm{~h}$; Arrhenius plot (b) and Eyring plot (c) for the SORs at different reaction temperatures with the NKC-3-800 as the catalyst; (d) shows the yield of SO versus content of graphitic N. Reaction condition: $15 \mathrm{mmol}$ styrene, $20 \mathrm{mg}$ catalyst, $16 \mathrm{ml}$ acetonitrile, $45 \mathrm{mmol}$ TBHP, $8 \mathrm{~h}$. 
$33.9 \mathrm{~kJ} \mathrm{~mol}^{-1}$ and $-164.2 \mathrm{~J} \mathrm{~mol}^{-1} \mathrm{~K}^{-1}$, respectively. And the $\Delta \mathrm{G}$ values according to the Eq. (3) obtained at $60,70,80$ and $90{ }^{\circ} \mathrm{C}$ were $88.6,90.2,91.9$ and $93.5 \mathrm{~kJ} \mathrm{~mol}^{-1}$, respectively.

\section{Conclusions}

In conclusion, we have developed radish-derived NKC catalysts with hierarchical porosity readily prepared by $\mathrm{N}$-doping with urea and activation with $\mathrm{KOH}$ at the same time. The catalytic results of both the NRR and SOR suggest that the reaction performances of the series of NKC catalysts exhibit significantly positive correlations with the content of graphitic $\mathrm{N}$ species rather than the total $\mathrm{N}$ content and the structural properties. Among all the catalysts, the NKC-3-800 is the most suitable one for these two reactions, presenting attractive catalytic results comparable to many metal or even precious metal catalysts. Encouragingly, in the NRR, it shows a TOF value reaching up to $1.67 \times 10^{-4} \mathrm{mmol} \mathrm{mg}^{-1} \mathrm{~min}^{-1}$, while a high SO yield of $64.0 \%$ is achieved in the SOR with a styrene conversion of $83.5 \%$ and a SO selectivity of $76.7 \%$. Furthermore, various kinetic and thermodynamic parameters were calculated for both reactions, and catalytic mechanisms were analyzed. Further experimental and theoretical calculation studies are encouraged to gain deeper molecular-level insights into the catalytic nature of these reactions. This study not only sheds a new light on the high value-added utilization of biomass, but also opens up more application possibilities of carbon-based catalysts derived from cheap and abundant biomass in practical organic reactions.

\section{References}

[1] I. Fechete, Y. Wang, J. C. Védrine, Catal. Today, 2012, 189, 2-27.

[2] X. Duan, H. Sun, S. Wang, Acc. Chem. Res., 2018, 51, 678-687.

[3] L. Dai, Adv. Mater., 2019, 31, 1900973.

[4] X. Duan, Z. Ao, H. Zhang, M. Saunders, H. Sun, Z. Shao, S. Wang, Appl. Catal. B, 2018, 222, 176-181.

[5] Q. Lv, W. Si, J. He, L. Sun, C. Zhang, N. Wang, Z. Yang, X. Li, X. Wang, W. Deng, Y. Long, C. Huang, Y. Li, Nat. Commun., 2018, 9, 3376.

[6] K. Mamtani, D. Jain, D. Dogu, V. Gustin, S. Gunduz, A. C. Co, U. S. Ozkan, Appl. Catal. B, 2018, 220, 88-97.

[7] Y. Chen, Z. Wang, S. Mao, Y. Wang, Chin. J. Catal., 2019, 40, 971-979.

[8] L. Xie, Z. Wang, J. Liu, Y. Gong, S. Mao, G. Lü, X. Ma, L. Yu, Y. Wang, Carbon, 2019, 155, 611-617.

[9] Y. Jia, L. Zhang, L. Zhuang, H. Liu, X. Yan, X. Wang, J. Liu, J. Wang, Y. Zheng, Z. Xiao, E. Taran, J. Chen, D. Yang, Z. Zhu, S. Wang, L. Dai, X. Yao, Nat. Catal., 2019, 2, 688-695.

[10] J. Zhang, L. Qu, G. Shi, J. Liu, J. Chen, L. Dai, Angew. Chem. Int. Ed., 2016, 55, 2230-2234.

[11] T. Jeong, H. Piao, S. Park, J.-H. Yang, G. Choi, Q. Wu, H. Kang, H. J. Woo, S. J. Jung, H. Kim, B. G. Shin, Y. Kim, E. H. Hwang, J.-H. Choy, Y. J. Song, Appl. Catal. B, 2019, 256, 117850.

[12] C. Li, Y. Wang, N. Xiao, H. Li, Y. Ji, Z. Guo, C. Liu, J. Qiu, Carbon, 2019, $151,46-52$.

[13] Y. Gao, G. Hu, J. Zhong, Z. Shi, Y. Zhu, D. S. Su, J. Wang, X. Bao, D. Ma, Angew. Chem. Int. Ed., 2013, 52, 2109-2113.

[14] J. Wang, F. Zhao, C. Zhang, L. Kang, M. Zhu, Appl. Catal. A, 2018, $549,68-75$.

[15] S. Shang, P.-P. Chen, L. Wang, Y. Lv, W.-X. Li, S. Gao, ACS Catal.,
2018, 8, 9936-9944.

[16] J. Liu, X. Yan, L. Wang, L. Kong, P. Jian, J. Colloid Interface Sci., 2017, 497, 102-107.

[17] L. Dai, Y. Xue, L. Qu, H.-J. Choi, J.-B. Baek, Chem. Rev., 2015, 115, 4823-4892.

[18] W. Pei, S. Zhou, Y. Bai, J. Zhao, Carbon, 2018, 133, 260-266.

[19] H. Zhao, Z.-P. Hu, Y.-P. Zhu, L. Ge, Z.-Y. Yuan, Chin. J. Catal., 2019, 40, 1366-1374.

[20] Y. Song, W. Chen, C. Zhao, S. Li, W. Wei, Y. Sun, Angew. Chem. Int. Ed., 2017, 56, 10840-10844.

[21] D. Guo, R. Shibuya, C. Akiba, S. Saji, T. Kondo, J. Nakamura, Science, 2016, 351, 361-365.

[22] S. Mao, C. Wang, Y. Wang, J. Catal., 2019, 375, 456-465.

[23] X. Duan, J. Xu, Z. Wei, J. Ma, S. Guo, S. Wang, H. Liu, S. Dou, Adv. Mater., 2017, 29, 1701784.

[24] T. Sharifi, G. Hu, X. Jia, T. Wågberg, ACS Nano, 2012, 6, 8904-8912.

[25] S. Zhou, X. Yang, W. Pei, N. Liu, J. Zhao, Nanoscale, 2018, 10, 10876-10883.

[26] S. Zhou, N. Liu, Z. Wang, J. Zhao, ACS Appl. Mater. Interfaces, 2017, 9, 22578-22587.

[27] K. Gong, F. Du, Z. Xia, M. Durstock, L. Dai, Science, 2009, 323, 760-764.

[28] J. Tong, W. Li, L. Bo, W. Wang, Y. Li, T. Li, Q. Zhang, H. Fan, Chin. J. Catal., 2018, 39, 1138-1145.

[29] S. Liu, H. Yang, X. Huang, L. Liu, W. Cai, J. Gao, X. Li, T. Zhang, Y. Huang, B. Liu, Adv. Funct. Mater., 2018, 28, 1800499.

[30] Y. Zhao, J. Liang, C. Wang, J. Ma, G. G. Wallace, Adv. Energy Mater., 2018, 8, 1702524.

[31] C. Zhao, S. Zhang, M. Han, X. Zhang, Y. Liu, W. Li, C. Chen, G. Wang, H. Zhang, H. Zhao, ACS Energy Lett., 2019, 4, 377-383.

[32] P. Yao, Y. Qiu, T. Zhang, P. Su, X. Li, H. Zhang, ACS Sustain. Chem. Eng., 2019, 7, 5249-5255.

[33] X. Li, B. Y. Guan, S. Gao, X. W. Lou, Energy Environ. Sci., 2019, 12, 648-655.

[34] F. Zhang, F. Yang, M. Hua, Z. Yang, H. Wei, Y. Yang, J. Wei, Chem. Mater., 2019, 31, 3812-3817.

[35] J. Liu, J. Li, R. Meng, P. Jian, L. Wang, J. Colloid Interface Sci., 2019, 551, 261-269.

[36] X. Wang, S. Chen, G. Reggiano, S. Thota, Y. Wang, P. Kerns, S. L. Suib, J. Zhao, Chem. Commun., 2019, 55, 1249-1252.

[37] Z. Yan, L. Fu, X. Zuo, H. Yang, Appl. Catal. B, 2018, 226, 23-30.

[38] J. Liu, Z. Wang, X. Yan, P. Jian, J. Colloid Interface Sci., 2017, 505, 789-795.

[39] C. Weerakkody, S. Biswas, W. Song, J. He, N. Wasalathanthri, S. Dissanayake, D. A. Kriz, B. Dutta, S. L. Suib, Appl. Catal. B, 2018, 221, 681-690.

[40] J. Liu, R. Meng, J. Li, P. Jian, L. Wang, R. Jian, Appl. Catal. B, 2019, 254, 214-222.

[41] L. Wang, J. Peng, Z. Tang, X. Kang, M. Fu, S. Chen, Appl. Catal. A, 2018, 557, 1-6.

[42] J. Liu, T. Chen, P. Jian, L. Wang, Chin. J. Catal., 2018, 39, 1942-1950.

[43] Y. Ji, Y. Shi, Y. Yang, P. Yang, L. Wang, J. Lu, J. Li, L. Zhou, C. Ferronato, J.-M. Chovelon, J. Hazard. Mater., 2019, 361, 152-161.

[44] N. Qiu, Y. Liu, M. Xiang, X. Lu, Q. Yang, R. Guo, Sensor Actuat. B, 2018, 266, 86-94.

[45] Y. Ma, X. Wu, G. Zhang, Appl. Catal. B, 2017, 205, 262-270.

[46] D. L. Sivadas, S. Vijayan, R. Rajeev, K. N. Ninan, K. Prabhakaran, Carbon, 2016, 109, 7-18.

[47] A. K. Mondal, K. Kretschmer, Y. Zhao, H. Liu, C. Wang, B. Sun, G. Wang, Chem. Eur. J., 2017, 23, 3683-3690.

[48] M. Wahid, G. Parte, D. Phase, S. Ogale, J. Mater. Chem. A, 2015, 3, 1208-1215. 


\title{
Graphical Abstract
}

Chin. J. Catal., 2020, 41: 1217-1229 doi: 10.1016/S1872-2067(20)63534-3

Versatile bifunctional nitrogen-doped porous carbon derived from biomass in catalytic reduction of 4-nitrophenol and oxidation of styrene

Jiangyong Liu*, Jinxing Li, Rongfei Ye, Xiaodong Yan, Lixia Wang, Panming Jian

Yangzhou University; Jiangnan University

$\mathrm{N}$-doped porous carbon derived from cheap and abundant radish can be employed as versatile and efficient bifunctional catalysts in both the catalytic reduction of 4-Nitrophenol and oxidation of styrene.

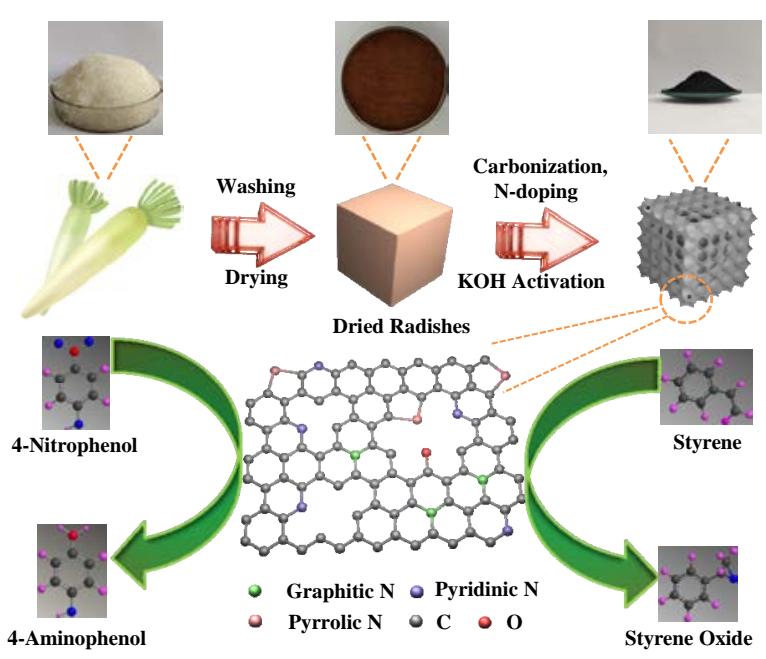

[56] J. Li, C. Liu, Y. Liu, J. Mater. Chem., 2012, 22, 8426-8430.

[57] W. Ye, J. Yu, Y. Zhou, D. Gao, D. Wang, C. Wang, D. Xue, Appl. Catal. $B, 2016,181,371-378$

[58] X.-K. Kong, Z.-Y. Sun, M. Chen, C.-L. Chen, Q.-W. Chen, Energy Environ. Sci, 2013, 6, 3260-3266.

[59] Y. Mei, Y. Lu, F. Polzer, M. Ballauff, M. Drechsler, Chem. Mater., 2007, 19, 1062-1069.

[60] P. Zhang, Y. Sui, G. Xiao, Y. Wang, C. Wang, B. Liu, G. Zou, B. Zou, J. Mater. Chem. A, 2013, 1, 1632-1638.

[61] X. Liu, J. Ding, X. Lin, R. Gao, Z. Li, W.-L. Dai, Appl. Catal., A, 2015, 503, 117-123.

[62] D. K. Dumbre, V. R. Choudhary, N. S. Patil, B. S. Uphade, S. K. Bhargava, J. Colloid Interface Sci., 2014, 415, 111-116.

[63] C. Huang, H. Zhang, Z. Sun, Y. Zhao, S. Chen, R. Tao, Z. Liu, J. Colloid Interface Sci., 2011, 364, 298-303.

\section{生物质基双功能氮掺杂多孔碳在对硝基苯酚还原和苯乙烯氧化中的应用}

\author{
刘江永 ${ }^{\mathrm{a},}$, 李金兴 ${ }^{\mathrm{a}}$, 叶荣飞 ${ }^{\mathrm{a}}$, 晏晓东 ${ }^{\mathrm{b}}$, 王理霞 ${ }^{\mathrm{a}}$, 菅盘铭 ${ }^{\mathrm{a}}$ \\ a扬州大学化学化工学院, 江苏扬州 225002 \\ b 江南大学化学与材料工程学院, 江苏无锡 214122
}

摘要: 大多数催化过程需以金属甚至贵金属作为活性位点, 尽管金属基催化剂在很多情况下可以展现出较好的催化性能, 但其实际应用受到价格较高、储量有限、组分流失和金属位点烧结等因素的限制. 在非金属催化剂中, 碳材料由于具有来 源丰富、稳定性好以及可调控性强等特点而得到了广泛应用. 研究表明, 将具有供电子或吸电子特征的异质原子如氮、硼、 硫和磷等掺入碳结构中是一种可行的策略, 可通过电子结构调控产生缺陷来提高催化性能. 其中, 氮原子与碳原子的原子 半径相近, 可有效改善碳的化学惰性, 是一种理想的掺杂原子. 基于这些认识, 各类氮掺杂碳材料, 如碳纳米管、碳纳米球、 石墨烯、介孔碳、碳纤维等已经被开发出来且显示出令人满意的催化效果. 然而, 传统氮掺杂碳材料的制备还存在反应条 件苛刻、需要使用各类有毒试剂以及制备过程复杂等缺点. 近年来, 以廉价易得的生物质为原料, 通过简单绿色方法合成 氮掺杂碳材料, 并进一步探索其在更多催化领域如有机催化中的应用得到了广泛关注.

对硝基苯酚的催化还原反应和苯乙烯的催化氧化反应一般需要金属催化剂. 其中, 对硝基苯酚是化学工业中常见的 
难降解污染物, 可对环境和人类健康造成严重威胁. 在所有减轻其污染和危害的方法中, 从环境和工业角度出发, 将其催 化还原成对氨基苯酚是最经济的方法. 苯乙烯的氧化反应可用于生产各类高附加值化学品, 例如环氧苯乙烷是合成增塑 剂、香料和药品等的重要中间体. 对于这两个反应, 开发高效的生物质基碳氮掺杂碳材料作为非金属催化剂仍具有挑战性. 本文以价廉易得的萝卜为原料, 通过耦合氮掺杂、碳化和氢氧化钾活化过程, 采用简单的一步法制备得到了一系列氮 掺杂多孔碳(NKC), 发现其在对硝基苯酚还原反应和苯乙烯氧化反应中均表现出良好的催化性能. NKC系列催化剂的比表 面积、孔体积和 $\mathrm{N}$ 掺杂含量分别为918.9-3062.7 $\mathrm{m}^{2} \mathrm{~g}^{-1}, 1.01-2.04 \mathrm{~cm}^{3} \mathrm{~g}^{-1}$ 和1.29-15.3 at\%. 综合表征结果和催化反应结果发 现, 催化性能与结构参数并不直接相关, 而是与催化剂中石墨化氮的含量呈正相关关系. 在NKC系列催化剂中, NKC-3-800 对于这两个反应的催化反应效果最佳, 其催化效果可达到或超过已报道的金属甚至贵金属催化剂. 此外, 本文还计算了两 个反应的各类动力学和热力学参数, 并分析了可能的催化反应机理. 本文不仅为生物质的高附加值利用提供了新的思路, 而且为廉价和丰富的生物质基碳催化剂在有机反应中的进一步应用开辟了更多的可能性.

关键词: 氮掺杂; 碳; 生物质; 对硝基苯酚; 苯乙烯

收稿日期: 2019-11-20. 接受日期: 2019-12-28. 出版日期: 2020-08-05.

*通讯联系人. 电子信箱: liujy@yzu.edu.cn

基金来源: 江苏省高等学校自然科学研究项目(17KJB530011); 江苏省博士后科研资助计划项目(2019K093); 江苏高校优势学科 建设工程资助项目(PAPD).

本文的电子版全文由Elsevier出版社在ScienceDirect上出版(http://www.sciencedirect.com/science/journal/18722067). 